\title{
JC Virus Infection: A Clinical Conundrum
}

\author{
Hajra Farooq ${ }^{1}$, Saifullah Khan Niazi², Misbah Noor² and Eijaz Ghani²
}

\begin{abstract}
John Cunningham virus (JCV), a member of polyomaviridae family, has been described as a cause of the progressive multifocal leukoencephalopathy (PML). It is a potentially fatal, disabling demyelinating infection of the brain occurring mostly in the setting of immunosuppression. A few cases of JCV-associated meningitis and encephalitis have been described in literature. We report a case presenting with laboured breathing and reduced conscious level, who after thorough investigations was diagnosed to be a case of PML.
\end{abstract}

Key Words: John Cunningham virus (JCV), Progressive multifocal leukoencephalopathy.

\section{INTRODUCTION}

JCV has a circular double-stranded DNA genome and was isolated in 1971 from the brain of a patient with Hodgkin disease.1,2 Astrom and colleagues described $\mathrm{JCV}$ as the etiological agent of the progressive multifocal leukoencephalopathy (PML), ${ }^{2}$ which is a potentially fatal or disabling demyelinating brain infection, mostly occurring in the immunosuppressed patients. ${ }^{3}$ The DNA of JCV has been found in the brain of both healthy and immunocompromised patients suggesting that JCV can maintain latency in the central nervous system (CNS) without any evidence of disease. ${ }^{1}$ The virus has a high seroprevalence worldwide but only a small subset of immunosuppressed individuals, especially those infected with HIVIAIDS, develop PML. 1

\section{CASE REPORT}

A 32-year female patient was admitted to the emergency room in June 2018 because of laboured breathing and reduced conscious level. She had been on medication for hypothyroidism since her childhood. According to her husband, she had decreased consciousness for the past 3 months, after which she developed weakness at the right side of her body that progressively involved to the whole body. Later, she also developed loss of speech. These symptoms deteriorated over the next three months. She had been married for 12 years with no children and one miscarriage about 10 years ago.

The neurological examination revealed a Glascow coma scale (GCS) of $5 / 15$ with right pupil being pinpoint and reactive. However, the left pupil was dilated and non-

1 Department of Virology, Chughtai Lab, Lahore, Pakistan

2 Department of Virology, Armed Forces Institute of Pathology (AFIP), Rawalpindi, Pakistan

Correspondence: Dr. Misbah Noor, Department of Virology, Armed Forces Institute of Pathology (AFIP), Rawalpindi,

Pakistan

E-mail: misbahnoor001@gmail.com

Received: September 04, 2018; Accepted: December 12, 2018 reactive. The rest of the systemic examination was normal except for the tachycardia (Heart rate: $96 / \mathrm{min}$ ). The initial laboratory investigations showed hemoglobin $(\mathrm{Hb})$ of $9.7 \mathrm{~g} / \mathrm{dl}$ and mean corpuscle volume (MCV) of $101 \mathrm{fl}$. The platelet count was $84 \times 10^{9} / \mathrm{L}$. The liver and renal function tests were normal. The anti-measles cerebrospinal fluid (CSF) antibodies test was negative. Screening tests for hepatitis B, hepatitis $C$ on 3rd generation enzyme-linked immunosorbant assay (ELISA) (BioRad) and HIV on $4^{\text {th }}$ generation Combo assay (BioRad) were negative. VDRL and TPHA for syphilis were also negative. The CSF examination revealed raised protein and glucose levels. The follicular stimulating hormone (FSH) and lutenizing hormone ( $\mathrm{LH})$ levels were low. Anti-tissue transglutaminase antibodies, protein electrophoresis and immunofixation for light chains were all negative. Echocardiography performed on the same day was normal with ejection fraction (EF) of $60 \%$. A provisional diagnosis of Wernicke's encephalopathy was made as the patient had vomiting, hypotension and adrenal insufficiency. The differential diagnosis also included space occupying lesion (SOL) of brain and thyroid storm.

The MRI brain (with contrast) showed cortical cysts, "heart of the gyrus" sign, acute demyelination with involvement of white matter (hyper intense changes) and periventricular changes. There was a suspicion that JCV might be responsible for the disease in this case. So the CSF sample was sent for JCV polymerase chain reaction (PCR). It was performed on next day using PCR kit of Gene Proof BK/JC Virus (BK/JC). The result showed that the DNA of JCV was detectable $(48,410$ $\mathrm{IU} / \mathrm{ml}$ ) in the CSF sample. The condition of the patient worsened during the next 24 hours and she was put on ventilator. Unfortunately, the patient expired two days later.

\section{DISCUSSION}

PML is a demyelinating brain disease that results from destruction of oligodendrocytes and astrocytes by JCV. PML was previously thought to occur exclusively in 
patients with HIVIAIDS with CD4 $<500 / \mathrm{mm}^{3}$ due to reactivation of JCV. Other manifestations include JCV granule cell neuronopathy (JCV GCN) or JCV encephalopathy (JCVE). ${ }^{4}$ Literature review shows that JCV positive PML has also been reported in HIV-negative patients. We have also reported here a case of JCV positive PML patient, who was HIV negative and there was no history of immunosuppression.

Dammeier et al. reported a case of PML in a 53-year caucasian woman with history of hypothyroidism. She presented initially with a focal epileptic fit and mild cognitive dysfunction. Brain biopsy specimen revealed the DNA of JCV along with histological findings. ${ }^{5}$ Agnihotri et al. described a case of JCV associated meningitis in a 67-year HIV-seronegative female, without any history of immunosuppression, who passed away five and a half months after the onset of symptoms. She presented initially with sudden onset of progressively worsening headache followed by vomiting. Her condition deteriorated over next two months with development of urinary incontinence, weakness in legs, lethargy and memory impairment. Almost similar symptoms and signs were also described by our patient. 6

Another case of a 69-year man with history of follicular lymphoma has been reported who presented with progressive dysarthria and right-sided paralysis. Similar presenting complaints were seen in this case. CSF routine analysis was insignificant. However, PCR for the DNA of JCV was detectable (500 copies $/ \mathrm{mL}$ ) in CSF. Brain biopsy showed chromatin margination and viropathic change within oligodendrocytes, confirming PML. 7

$\mathrm{JC}$ viremia is common in the general population, but PML does not develop in healthy immunocompetent individuals. In patients who become immuno-suppressed, the presence of JC viremia is a risk factor for PML. Currently, there is no effective therapy for PML and further studies are needed to find the medical management of PML. Regardless of the medical history, the outcome for the majority of patients is still very poor, as in this case.

This case report highlights the need to keep in mind uncommon infections like JCV in all patients presenting with neurological manifestations. Empiric treatment for PML should be considered at the earliest, as PML can be rapidly fatal.

\section{REFERENCES}

1. Ferenczy MW, Marshall LJ, Nelson CD, Atwood WJ, Nath A, Khalili $\mathrm{K}$, et al. Molecular biology, epidemiology, and pathogenesis of progressive multifocal leukoencephalopathy, the JC virus-induced demyelinating disease of the human brain. Clin Microbiol Rev 2012; 25:471-506.

2. Bellizzi A, Anzivino E, Rodio DM, Palamara AT, Nencioni L, Pietropaolo V. New insights on human polyomavirus JC and pathogenesis of progressive multifocal leukoencephalopathy. Clin Dev Immunol 2013; 2013:839719.

3. Carruthers RL, Berger J. Progressive multifocal leukoencephalopathy and JC virus-related disease in modern neurology practice. Mult Scler Relat Disord 2014; 3:419-30.

4. Gheuens S, Wüthrich C, Koralnik IJ. Progressive multifocal leukoencephalopathy: Why gray and white matter. Annu Rev Pathol 2013; 8:189-215.

5. Dammeier N, Schubert V, Hauser TK, Bornemann A, Bischof F. Case report of a patient with progressive multifocal leukoencephalopathy under treatment with dimethyl fumarate. $B M C$ Neurol 2015; 15:108.

6. Agnihotri SP, Wuthrich C, Dang X, Nauen D, Karimi R, Viscidi R, et al. A fatal case of JC virus meningitis presenting with hydrocephalus in a human immunodeficiency virus-seronegative patient. Ann Neurol 2014; 76:140-7.

7. Silverio KA, Patel SA. Progressive multifocal leukoencephalopathy with negative JC virus PCR following treatment of follicular lymphoma: Implications for biologics in the era of targeted cancer therapy. Case Rep Oncol Med 2015; 2015: 534529 . 